\title{
Sinonimias en el género Chaptalia (Asteraceae), con una clave ACTUALIZADA DE LAS ESPECIES ARGENTINAS
}

\author{
LILIANA KATINAS ${ }^{1}$, MAIRA S. VITALI ${ }^{1}$ y MARÍA JOSÉ APODACA ${ }^{1}$
}

\begin{abstract}
Summary: Synonymy in the genus Chaptalia (Asteraceae), with an updated key to the Argentinian species. The synonymy among Chaptalia graminifolia, C. mandonii, C. piloselloides, and C. runcinata is established under the name C. piloselloides. A re-description, illustration, and distribution map of $C$. piloselloides together with a key to the Argentinian species of Chaptalia are presented.
\end{abstract}

Key words: Compositae, Chaptalia piloselloides, Mutisieae, taxonomy.

Resumen: Se establece la sinonimia entre las especies Chaptalia graminifolia, C. mandonii, C. piloselloides y $C$. runcinata, bajo el nombre de C. piloselloides. Se presenta una re-descripción de C. piloselloides con ilustración y mapa de distribución de la especie y una clave actualizada de las especies argentinas de Chaptalia.

Palabras clave: Compositae, Chaptalia piloselloides, Mutisieae, taxonomía.

\section{INTRODUCCIÓN}

El género Chaptalia Vent. (Asteraceae, Mutisieae) posee aproximadamente 40 especies, se distribuye desde el sur de los Estados Unidos hasta el centro de la Argentina, y se distingue de otros géneros de Mutisieae por su hábito herbáceo con hojas en roseta basal, escapo floral y tres tipos de flores en sus capítulos.

La taxonomía del género es compleja probablemente por el balance entre reproducción sexual (chasmogamia y cleistogamia) y asexual (apomixis y por rizomas) que existe en muchas especies de Chaptalia. Otros factores que dificultan la distinción morfológica entre los taxones son la ocurrencia de hibridación entre especies y variedades y la poliploidía. Por ello, es común que existan complejos de especies en Chaptalia con una gran variabilidad específica y límites interespecíficos difusos (Katinas \& Zavaro, 2014a, b).

En estudios previos sobre este género (Katinas,

${ }^{1}$ División Plantas Vasculares, Museo de La Plata (FCNyM, UNLP), Paseo del Bosque s/n, 1900 La Plata, Argentina. katinas@fcnym.unlp.edu.ar
1996; Pasini et al., 2014) se encontraron dificultades para hallar diferencias morfológicas entre Chaptalia graminifolia (Dusén ex Malme) Cabrera (este de Brasil hasta Minas Gerais y São Paulo), C. mandonii Sch. Bip. ex Burkart (noroeste de Argentina, Bolivia y Brasil), C. piloselloides (Vahl) Baker (sur de Brasil, Uruguay, Paraguay y este de Argentina) y C. runcinata Kunth (desde México hasta Argentina). Baird et al. (2010) realizaron un análisis filogenético con datos moleculares $(\operatorname{trn} \mathrm{L}$ $r p$ L32 intron e ITS) del género Leibnitzia Cass., el cual forma parte del complejo Gerbera (Katinas, 2004) junto con Chaptalia y otros géneros. En el análisis se incluyeron siete especies de Chaptalia, entre ellas $C$. mandonii y $C$. runcinata. Tanto los análisis individuales como los combinados muestran a Chaptalia como género monofilético y distintas relaciones entre $C$. mandonii y $C$. runcinata con las otras especies, pero en ningún análisis estas especies resultan hermanas entre sí. Tal como lo mencionan Baird et al. (2010), estos resultados representan un grado de avance pero no pueden considerarse concluyentes, especialmente por el escaso número de especies de Chaptalia muestreadas y por los bajos o directamente ausentes valores de soporte en muchas ramas de Chaptalia. 
Perdicium piloselloides Vahl, el basónimo de Chaptalia piloselloides, es descripto por Vahl en 1793 sobre la base de un ejemplar de Montevideo (Uruguay), y en 1820 Kunth propone la nueva especie C. runcinata para los Andes de Colombia. En 1865 Schultz Bipontinus incluye el nombre C. mandonii en una lista de especies de Bolivia, pero no describe a la especie. Baker (1884) en su tratamiento de Chaptalia para Brasil, no incluye a C. runcinata en la sinonimia de $C$. piloselloides pero sí menciona ejemplares de Venezuela, una distribución que se correspondería con la de C. runcinata, evidenciando la superposición morfológica entre ambas entidades. Por otro lado, incluye el tipo de C. mandonii (Mandon 11, M) en el material de C. piloselloides. En 1933 Dusén establece Chaptalia piloselloides (Vahl) Baker var. graminifolia Dusén por sus hojas largas, angostas $(10-20 \times 0,3-0,5 \mathrm{~cm})$ y enteras o sub-enteras y sus escapos de $30 \mathrm{~cm}$ de longitud. Posteriormente, Burkart (1944) en su revisión del género Chaptalia pasa esta variedad a C. runcinata como Chaptalia runcinata Kuntze var. graminifolia (Dusén) Burkart sobre la base de su cipsela con cinco costillas. En este trabajo, Burkart describe legítimamente C. mandonii y menciona la afinidad morfológica entre esta especie, C. piloselloides y C. runcinata. Distingue C. piloselloides de C. runcinata por su mayor robustez, el pedúnculo de mayor diámetro, las filarias del involucro más anchas, los aquenios con más costillas y el rostro más grueso y menos netamente separado de la parte fértil. Asimismo comenta que cuando se comparan ejemplares que habitan la provincia de Buenos Aires ambas especies se distinguen fácilmente, pero en el sur de Brasil las diferencias ya no son notorias y existen ejemplares intermedios que Burkart interpreta como híbridos. En la fotografía n. 16007 de un material del herbario $B$ se puede ver una etiqueta escrita por Burkart donde establece la var. runcinata y en B 16005 la subsp. mandonii, ambas entidades como taxones infraespecíficos de C. piloselloides. Aunque nunca publicó las descripciones de esos taxones, es evidente que veía una estrecha relación morfológica entre estas especies. Finalmente, Cabrera \& Klein (1973) en la flora de Santa Catarina, Brasil, elevan la variedad graminifolia al status de especie como Chaptalia graminifolia (Dusén) Cabrera, por las hojas más comprimidas, siempre enteras y de consistencia más dura. Los autores comentan en este trabajo que existen formas intermedias entre $C$. graminifolia y $C$. runcinata, tal vez de transición de una especie a otra o entre híbridos naturales.

\section{Materiales y Métodos}

Este estudio fue realizado sobre la base de los materiales tipo y no tipo, imágenes digitales y fotografías de los siguientes herbarios (acrónimos de acuerdo con Holmgren et al., 1990): BAA, BR, C, F, GH, GOET, K, LP, M, MO, NY, P, S, SI, US.

Para el análisis de los materiales, las flores y frutos se hirvieron en agua para realizar su medición y disección, luego se aclararon en hipoclorito de sodio diluido y se colorearon con safranina al $2 \%$. El montaje se realizó con glicerina diluida al $10 \%$.

Las observaciones y los dibujos de hojas, flores y frutos se realizaron con la ayuda de una cámara clara adicionada a una lupa binocular Nikon SMZ 1000. Los dibujos fueron realizados por las autoras. Se hicieron observaciones de campo.

\section{Resultados y Discusión}

Nuestras observaciones sobre los materiales de estas cuatro especies demuestran que todos los caracteres mencionados para diferenciarlas se hallan combinados entre sí y no hallamos otros caracteres para distinguir estos taxones. De acuerdo con todos los estudios previos, Chaptalia piloselloides y $C$. runcinata se distinguirían de C. graminifolia por las hojas más cortas, anchas y dentadas o runcinadas y pelos en la base de sus frutos, en tanto que las hojas son graminiformes, lineares y enteras, y los frutos serían totalmente glabros en $C$. graminifolia. Observaciones al microscopio óptico de los frutos de ejemplares de Santa Catarina en Brasil con las características foliares de C. graminifolia muestran que muchos de ellos pueden tener pelos en su base que difícilmente se ven a simple vista (e.g., Reitz $\&$ Klein 3651, LP); esto se repite en ejemplares lejanos a la localidad típica de esta especie, como Misiones (Montes 4178, LP) y la provincia de 
Buenos Aires (Guerrero 175, LP). Asimismo, el análisis de muchos ejemplares muestra que existe una transición en la forma del limbo que va desde hojas cortas y obovadas a largas y lineares.

Por otro lado, las diferencias más importantes que se han utilizado para diferenciar Chaptalia piloselloides de C. runcinata son las filarias del capítulo anchas, el rostro grueso y 7-8 costillas en el fruto de $C$. piloselloides, mientras que C. runcinata tendría las filarias más angostas, y frutos con rostros filiformes y 4-6 costillas. Sin embargo, hay ejemplares colectados dentro del área de distribución de $C$. runcinata que comparten características con C. piloselloides, como el ejemplar de Paraguay (Soria 3961, MO) que posee frutos con rostro grueso y filarias muy estrechas. También hay plantas que en un mismo capítulo tienen frutos con seis costillas y otros con siete costillas (Lanfranchi 715, LP), y plantas que poseen frutos con rostros gruesos y cinco costillas (Schinini 1156, LP).

El único carácter diferencial de C. mandonii respecto a las otras tres especies sería que tiene hojas elípticas a oblanceoladas y su frutos completamente cubiertos de pelos. Sin embargo, se han hallado plantas con hojas graminiformes y frutos totalmente pubescentes (Brade 16890, LP) y plantas con pelos que alcanzan la mitad del fruto (Morrone et al. 3769, SI), siendo entonces difícil definir a qué especie pertenece. También se estudiaron ejemplares con los frutos totalmente cubiertos de pelos pero lejanos a las localidades típicas de la especie, como el ejemplar de Corrientes: Cabrera 11913 (LP).

Debido a que no se pueden diferenciar morfológicamente las cuatro especies, se establece en este trabajo la sinonimia entre $C$. graminifolia, C. mandonii, C. piloselloides y C. runcinata bajo el nombre de Chaptalia piloselloides que es el que corresponde por el principio de prioridad (McNeill et al., 2012).

\section{Tratamiento taxonómico}

Chaptalia piloselloides (Vahl) Baker, in Martius Fl. bras. 6: 378. 1884. (Fig. 1).

Perdicium piloselloides Vahl, Skr. Naturhist. Selsk. 2: 38, tab. 5. 1793, non Perdicium piloselloides (L.) Hiern., 1898 [= Gerbera piloselloides (L.) Cass]. Tussilago sinuata Pers. var. piloselloides (Vahl) Pers., Syn. pl. 2: 456. 1807. Thyrsanthema [pilosellodes] piloselloides (Vahl) Kuntze, Revis. gen. pl. 1: 369. 1891. Tipo: Amer. Merid., au pied du morne de Monte Video, V-1763, Commerson (holotypus P, imagen digital!; isotypus $\mathrm{C}$, imagen digital!).

Chaptalia runcinata Kunth in Humb., Bonpl. \& Kunth, Nov. gen. sp 4. (folio ed.): 5. 1818. Thyrsanthema runcinata (Kunth) Kuntze, Revis. gen. pl. 1: 369. 1891. Tipo: Colombia, Humboldt et Bonpland 2031 [lectotypus $\mathrm{P}$ designado por Nesom (1995), imagen digital!, fotografía F $n$. 38167 en $\mathrm{F}$ !, $\mathrm{MO}$ !); isotypi $\mathrm{P}$, imágenes digitales!).

Loxodon longipes Cass., Dict. sci. nat. 27: 255. 1825 , nom. illeg.

Oxydon bicolor Less., Linnaea 5: 357. 1830, nom. illeg. Tussilago bicolor Less., Linnaea 5: 357. 1830, nom. illeg. Gerbera bicolor (Less.) Sch.Bip., in Seeman Bot. Voy. Herald: 313. 1856, nom. illeg.

Lieberkuhna bracteata Cass. f. minor Chodat, Bull. Herb. Boissier 2: 400. 1903. Lieberkuhna bracteata Cass., Dict. sci. nat. 26: 287. 1823, nom. illeg. Gerbera bracteata (Cass.) Sch.Bip., in Seeman Bot. Voy. Herald: 313. 1856, nom. illeg. Chaptalia piloselloides (Vahl) Baker subsp. bracteata (Cass.) Burkart, Revista Fac. Agron. Veterin. 7: 249. 1934, nom. illeg. Tipo: Paraguay, in palude Tucangua, sept., Hassler 3280 (holotypus probablemente en $\mathrm{G}$ ).

Chaptalia piloselloides (Vahl) Baker var. graminifolia Dusén ex Malme, Kongl. Svenska. Vetensk. Acad. Handl., n.s. 12 (2): 115. 1933. Chaptalia runcinata Kunth var. graminifolia (Dusén) Burkart, Darwiniana 6: 556. 1944. Chaptalia graminifolia (Dusén ex Malme) Cabrera, Fl. Ilustr. Catarinense 1: 60. 1973. Tipo: Brasil, Paraná, inter Capão Grande et Villa Velha, 12-III-1904, Dusen 4062 [lectotypus B, designado por Burkart (1944) probablemente destruido, fotografía F n. 16003!; duplicado de lectotypus GH!]. Paratypi: Brasil, Paraná, Jaguarariaiva, 21V-1914, Dusén 406a (F!, GH!, SI!, US!). Brasil, Paraná, Jaguariahyva, in ripa fluminis, 5-VII1910, Dusén 10037 (M!; S, imagen digital!). Brasil, Paraná, Curityba, in campo, 2-IX-1909, Dusén 8796 (S, imagen digital!).

Chaptalia mandonii Sch. Bip. ex Burkart, Darwiniana 6: 551. 1944. Leria mandoni Sch. Bip., Bull. Soc. Bot. France 12: 79. 1865, nom. 
illeg. Tipo: Bolivia, Larecaja, en la vecindad de Sorata, monte Chilica, 3000 m, X-1858, Mandon 11 (holotypus B, probablemente destruido, fotografía F n. 16005 en F!, GH!, MO!; isotypi BR, GH, GOET, K, NY, P, S, imágenes digitales!).

Hierbas perennes, acaules, escaposas, de 3-40 $\mathrm{cm}$ de alt., rizomas de 0,3-3,5 cm long. Hojas dispuestas en una roseta basal, lámina de 0,7-33,5 x 0,3-2 cm, linear-oblanceoladas, oblanceoladas, elípticas, elíptico-oblanceoladas, espatuladas, margen entero, mucronulado, crenado, retrorsodentado o runcinado, plano o revoluto, ápice agudo u obtuso, sésiles o base más o menos atenuada en un pseudopecíolo o pecíolo alado, glabras o escasamente pubescentes en el haz, blanco-amarillentas, blanco-verdosas, o blancotomentosas en el envés. Escapos uno a varios por planta, de 7-38 cm long., blanco-tomentosos, comúnmente algo ensanchados hacia la base del capítulo, con brácteas lineares, más numerosas hacia el ápice. Capítulos solitarios, erectos, sub-discoideos, heteromorfos, heterógamos, de 10-28 x 6-20 cm, turbinados a hemisféricos cuando están con frutos. Receptáculo desnudo, glabro. Filarias del involucro multiseriadas, verdosas o castaño-rojizas, glabras o escasamente pubescentes; primera serie de 3-6 x 0,3-1 mm, lineares, linear-lanceoladas, deltoideas, agudas en el ápice; segunda serie de 4-9 x 0,5-2 mm, linear-lanceoladas, lanceoladas, agudas en el ápice; tercera serie de 5-18 x 0,8-2 mm, linearlanceoladas, lanceoladas, oblongas, agudas en el ápice, escariosas en el margen; cuarta y quinta serie de 10-23 x 0,8-2 mm, linearoblongas, linear- lanceoladas, oblongas, agudas o largamente atenuadas en el ápice, escariosas en el margen. Flores trimorfas (ocasionalmente dimorfas), 15-80, corolas blancas, comúnmente con tintes rosados en el ápice, papilosas; flores del margen (ocasionalmente ausentes) femeninas, más cortas, de igual longitud, o más largas que el involucro, corola ligulada, a veces con un brevísimo labio interior, tubo de 2-3,5 mm long., lígula 3-dentada, de 2-9,5 $\mathrm{mm}$ long., linear, lanceolada, estilo de 5-7 mm long., bilobado o con ramas lineares, de 0,2-1 $\mathrm{mm}$; flores intermedias femeninas, corola filiforme 1-3,5 mm long., estilo de 5-7 mm long, bilobado o con ramas lineares, de 0,2-1,2 $\mathrm{mm}$; flores del centro hermafroditas, tubulosas o tubuloso-bilabiadas, tubo de 3,5-7 mm long., 5-lobadas en el ápice o con labio exterior 3-dentado y el interior 2-dentado, lóbulos o labios de 0,5-1,5 mm long, estilo de 5-7,2 mm long, bilobado o con ramas lineares, de 0,3-1,2 mm long, anteras de 1,8-2,8 $\mathrm{mm}$ long, prolongadas en dos colas glabras, de 0,2-1,2 $\mathrm{mm}$ long, filamentos glabros, apéndice conectival oblongo, entero. Cipselas elípticas, cilíndricas, castañas o a veces purpúreas, con 4-10 costillas, glabras, completamente pubescentes, o pubescentes sólo en la base, porción seminal de 3-9,5 mm long, rostro grueso o filiforme, de 0,5-5 mm long. Papus formado por numerosas cerdas escabrosas, de 5-11 mm long, blancoamarillentas, amarillo-rojizas, anaranjadas. $2 n=$ ca. 48 (Wulff et al., 1996), 48+0-1 (Watanabe et al., 2007).

Distribución y Hábitat: Desde México a Argentina; no se han hallado ejemplares de Perú. Crece en suelos rocosos, arenosos y en campos graminosos, desde el nivel del mar hasta los $3000 \mathrm{~m}$. Los ejemplares de hojas alargadas aparecen con más frecuencia en la distribución más austral (Brasil, Uruguay, Argentina) y suelen vegetar en suelos húmedos o cerca de arroyos o ríos. Dada su extensa distribución geográfica, la floración ocurre todo el año; en nuestro país se da comúnmente de marzo a octubre, pudiendo extenderse hasta diciembre en el noroeste.

Nombres vulgares: "cerraja", "folha de grama", "lengua de vaca", "língua de vaca".

Obs.: En ocasiones Chaptalia piloselloides puede confundirse con $C$. exscapa caracterizada por sus escapos brevísimos (e.g., algunos ejemplares de Uruguay como Gallinal et al. 4414, LP, MO), sobre todo en los ejemplares jóvenes que aún no han desarrollado bien su escapo. En estas condiciones, Chaptalia piloselloides se distingue de $C$. exscapa por sus cipselas largamente rostradas y generalmente pubescentes en la base. Chaptalia piloselloides también puede parecerse a C. modesta por sus pedúnculos ensanchados en la base del capítulo, pero en esta última la lámina de la hoja se angosta abruptamente antes del pecíolo alado (vs. una transición gradual en C. piloselloides) y su época de floración va desde 


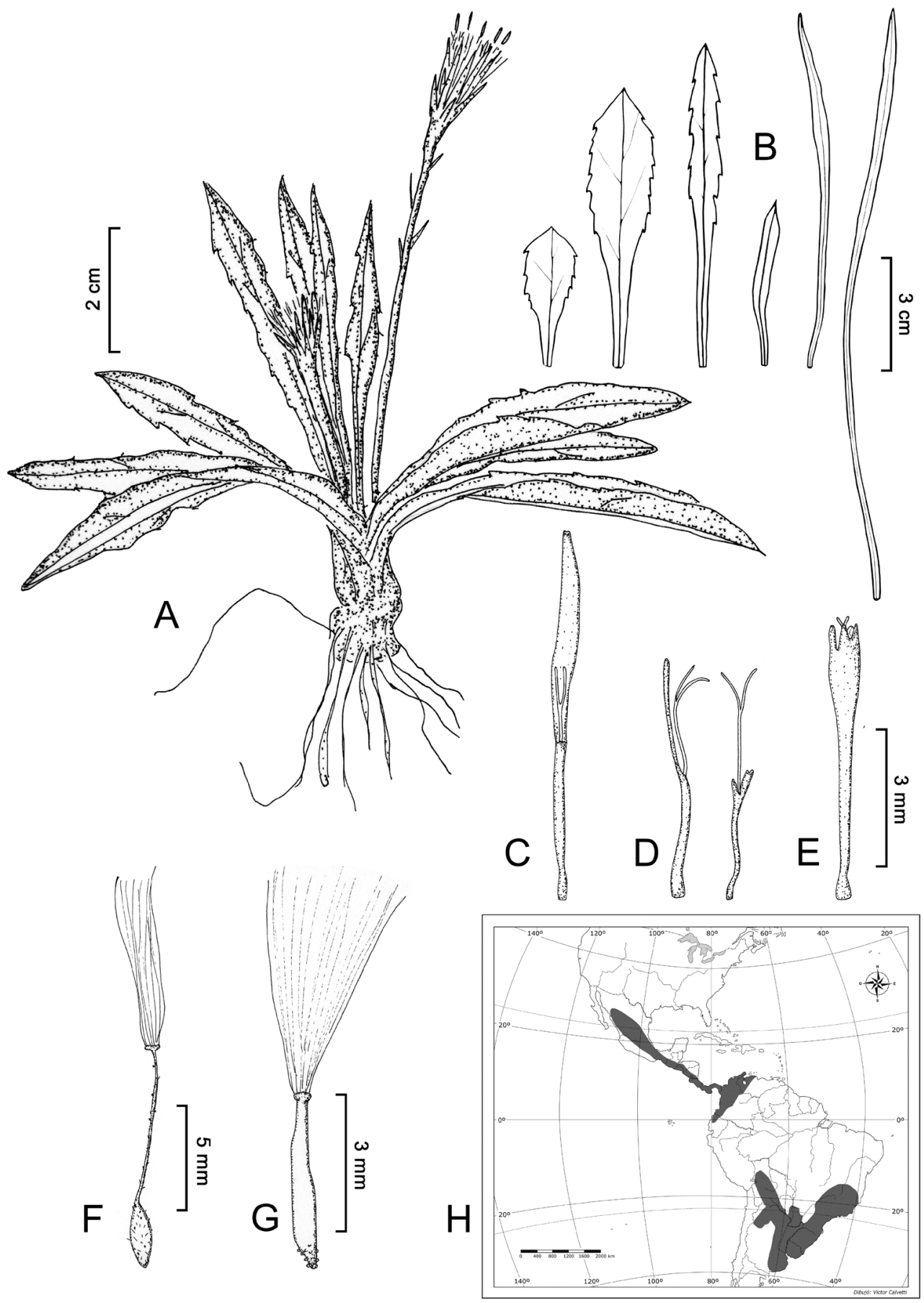

Fig. 1. Chaptalia piloselloides (Vahl) Baker. A: Hábito. B: Variabilidad foliar. C-E: Flores de un mismo capítulo. C: Flor femenina del margen. D: Flores femeninas intermedias mostrando las distintas longitudes de la corola. E: Flor hermafrodita central. F-G: Frutos y papus. F: Fruto con rostro filiforme. G: Fruto con rostro grueso. H: Mapa de distribución. A: Basualdo 3961 (MO). B: Schinini 1156 (LP), Clos 6532 (LP), Brade 16890 (LP), Jolly et al. 453 (LP), Hatschbach 43016 (MO). C-F: Jolly et al. 453 (LP). G: Oliveira 305 (US). 
diciembre a marzo (vs. marzo a octubre).

En los ejemplares de C. piloselloides con capítulos de flores dimorfas, las corolas de las flores más externas son intermedias entre una ligulada y una filiforme, acercándose más a una ligulada.

Muchos nombres ilegítimos incluidos en la sinonimia de C. piloselloides (e.g., Loxodon longipes Cass., Oxydon bicolor Less.) son nombres superfluos establecidos sobre la base del mismo ejemplar tipo sobre el que Kunth describió C. runcinata, y también son ilegítimas las combinaciones basadas en estos nombres.

Material adicional estudiado de Argentina: Prov. Buenos Aires: Partido Avellaneda, Sarandí, FCS, 16-VI-1928, Burkart 2208 (SI); Wilde, FCS, III-1929, Burkart 3825 (SI). Partido Escobar, Garín, FCCA, 18-IV-1948, Lanfranchi 715 (LP). Partido General Sarmiento, Bella Vista, FCS, 16-IV-1938, Clos 6532 (LP). Partido La Plata, Elizalde, cerca de La Plata, 7-VIII-1929, Cabrera 907 (LP); Villa Garibaldi, 14-IV-2013, Guerrero 341 (LP); alrededores de City Bell, barrio Grand Bell, 3-VI-2006, Katinas 216 (LP); Parque Pereyra Iraola, cerca de la estación del tren, 2-VI-2012, Guerrero 175 (LP). Partido Lobos, Lobos, 20-IV-1953, Fabris 632 (LP). Partido Pergamino, Estancia Buena Vista, 1-V-1916, Niedfeld s.n. (BAA). Partido Pilar, Rosas, El Toro, FCS, 4-V-1926, Daguerre 401 (SI). Partido San Vicente, San Vicente, FCS, IV-1927, Burkart 3135 (SI). Partido Tandil, Tandil, FCS, XI-1928, Burkart 3826 (SI). Partido Tigre, Tigre, 11-V1942, Burkart 12149 (SI); Partido Tornquist, Sierra de la Ventana, 24-V-1938, Cabrera 4452 (LP). Partido Veinticinco de Mayo, Valdez, 30-X1928, Burkart 3125 (SI). Prov. Catamarca: Dpto. Andalgalá, Cuesta de Mina Capillitas, 30-I-1974, Cabrera et al. 24738 (LP). Prov. Chaco: Dpto. Primero de Mayo, Colonia Benítez, VI/VII-1930, Schulz 38 (LP). Dpto. San Fernando, Fontana, V-1937, Meyer 2305 (LP). Dpto. Veinticinco de Mayo, Napalpí, VII-1935, DONAB 67 (SI). Prov. Corrientes: Dpto. Capital, 11-IV-1937, Meyer 2287 (LP); 19 km NE de Corrientes, ruta 12, camino a Santa Ana, 27-VI-1986, Schinini et al. 24782 (F). Dpto. Empedrado, Estancia "La Yela", 9-VI-1956, Pedersen 3928 (LP). Dpto. General Paz, Lomas de Vallejos, 29-VIII-1973,
Schinini \& Quarín 6988 (LP). Dpto. Ituzaingó, sin loc., 3/5-VII-1974, Krapovickas et al. 25622 (F, LP). Dpto. Mburucuyá, Estancia "Santa Teresa", 24-V-1952, Pedersen 1732 (LP, MO, US). Dpto. San Cosme, camino a Pto. González, $4 \mathrm{~km}$ E del cruce a Paso de la Patria, 19-V-1974, Krapovickas \& Cristóbal 25422 (LP). Dpto. Santo Tomé, Estancia Garruchos, 21-X-1954, Cabrera 11913 (LP). Prov. Entre Ríos: Dpto. Concordia, Concordia, hacia el S, 21-V-1964, Burkart et al. 25513 (SI). Dpto. Gualeguaychú, Gualeguaychú, aeródromo, 17-IV-1965, Burkart et al. 25812 (SI). Dpto. Federación, Chajarí, 25-IV-1952, Nicora 6188 (SI). Dpto. Feliciano, Feliciano, 19-V-1964, Burkart et al. 25487 (SI). Dpto. Tala, chacra Azarién, 8-I-1963, Sorarú 121 (SI). Dpto. Concepción del Uruguay, est. Río Uruguay, cerca de Gualeguaychú, 9-IV1963, Burkart \& Troncoso 24268 (LP, SI). Prov. Formosa: Dpto. Formosa, Guaycolec, VI-1919, Jörgensen 3360 (SI). Prov. Jujuy: Dpto. Capital, Mina 9 de Octubre, Sierra de Zapla, cerro de la Cruz, 13-IV-1974, Cabrera \& Kiesling 24945 (LP). Dpto. Humahuaca, Humahuaca, 31-I-1974, Kiesling et al. 778 (LP). Dpto. Valle Grande, Santa Ana, 20-I-1974, Kiesling et al. 772 (LP). Prov. La Rioja: Dpto. Chilecito, Cuesta de Guanchin, 26-I-1974, Cabrera et al. 24604 (LP). Prov. Misiones: Dpto. Candelaria, Candelaria, 26-VII-1974, Ahumada \& Eskuche 3194 (SI). Dpto. Caniguás, Puerto Rico, 22-V-1949, Montes 3965 (LP). Dpto. San Ignacio, San Ignacio, 31VII-1913, Quiroga s.n. (SI). Prov. Salta: Dpto. Rosario de Lerma, Campo Quijano, 18-XI-1942, Burkart 13267 (GH, SI). Dpto. Santa Victoria, ruta prov. $19,10 \mathrm{~km}$ de Los Toldos camino a Lipeo, 19-XI-2001, Morrone et al. 3769 (LP). Prov. Santa Fe: Dpto. General Obligado, Villa Guillermina, 21-IX-1939, Meyer 2948 (LP); Reconquista, 15-IV-1935, Burkart s.n. (SI). Prov. Tucumán: Dpto. Tafí, Sierra del Cajón, 29-IV1926, Venturi 6900 (US); Cumbre de Taficillo, 20-IV-1930, Venturi 10418 (GH).

Debido a los cambios aquí propuestos y a la sinonimia establecida entre Chaptalia integerrima y $C$. sinuata en un trabajo previo (Pasini et al., 2014) que involucra especies de nuestro país, se realiza una clave actualizada de las especies argentinas del género Chaptalia. 


\section{Clave de las especies argentinas del género Chaptalia}

1. Capítulos maduros sésiles o sostenidos por escapos brevísimos (2-3 cm long). Cipselas con un leve estrangulamiento subapical.

C. exscapa

1'. Capítulos maduros sostenidos por escapos largos (mayores de $3 \mathrm{~cm} \mathrm{long).} \mathrm{Cipselas} \mathrm{con} \mathrm{rostro} \mathrm{conspicuo.}$

2. Escapos sin hojas reducidas o brácteas.

3. Hojas liradas o pinnatisectas, con el lóbulo terminal más grande que los laterales.

C. nutans

3'. Hojas enteras o con el margen crenado, lobulado o retrorso-dentado pero nunca liradas ni pinnatisectas. C. integerrima

2'. Escapos con hojas reducidas o brácteas.

4. Hojas con la superficie adaxial rugosa. Escapos con muchas brácteas (más de 20).

C. arechavaletae

4'. Hojas con la superficie adaxial lisa. Escapos con pocas brácteas (hasta ca. 15).

5. Escapos ensanchados en su inserción con el capítulo.

6. Base de la lámina foliar redondeada, abruptamente angostada en el pecíolo alado.

C. modesta

6' Base de la lámina foliar atenuada, gradualmente transformándose en el pecíolo alado, u hojas sésiles. C. piloselloides

5'. Escapos del mismo grosor en toda su longitud, no ensanchados en su inserción con el capítulo.

7. Hojas pinnatisectas, a veces sólo tienen el lóbulo superior por reducción de los lóbulos

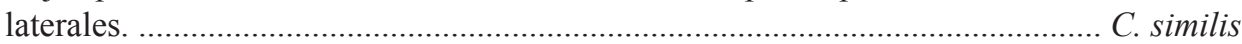

7'. Hojas enteras, con el margen crenado a lobulado, pero no pinnatisectas. ............... ignota

\section{Agradecimientos}

Agradecemos a los revisores y al editor por las sugerencias al manuscrito original. Este trabajo se realizó gracias al apoyo del Consejo Nacional de Investigaciones Científicas y Técnicas (CONICET), Agencia Nacional de Promoción Científica y Tecnológica (ANPCyT, PICT 1683), y Facultad de Ciencias Naturales y Museo, UNLP.

\section{Bibliografía}

BAIRD, K. E., V. A. FUNK, J. WEN \& A. WEEKS. 2010. Molecular phylogenetic analysis of Leibnitzia Cass. (Asteraceae: Mutisieae: Gerbera-complex), an Asian-North American disjunct genus. J. Syst. Evol. 48: 161-174.

BAKER, J. G. 1884. Compositae III. Mutisiaceae. In: MARTIUS, C. F. P. (ed.), Flora Brasiliensis 6(3), pp. 339-398. Monachii in typographia regia C. Wolf et fil. et in offic. lithograph. B Keller, Munich.
BURKART, A. 1944. Estudio del género de Compuestas Chaptalia con especial referencia a las especies argentinas. Darwiniana 6: 505-594.

CABRERA, A. L. \& R. M. KLEIN. 1973. Compostas. Tribo: Mutisieae. In: REITZ, P. R. (ed.), Fl. Il. Catarinense 1, pp. 3-124. Conselho Nacional de Pesquisas, Instituto Brasileiro de Desenvolvimento Florestal, Herbário Barbosa Rodrigues, Itajaí, Brasil.

HOLMGREN, P. K., N. H. HOLMGREN \& L. C. BARNETT. 1990. Index Herbariorum, Part I: The herbaria of the world. 8th ed. Bronx: New York Botanical Garden.

KATINAS, L. 1996. Tribu XII. Mutisieae. Subtribu 3. Mutisiinae. In: HUNZIKER, A. T. (ed.), Fl. Fanerog. Argentina, fasc. 4, pp. 1-40. PROFLORA, Córdoba, Argentina.

KATINAS, L. 2004. The Gerbera-complex (Asteraceae, Mutisieae): To split or not to split. Sida 21: 935-940.

KATINAS, L. \& C. ZAVARO. 2014a. Endemism and taxonomy of Chaptalia (Asteraceae) in the Caribbean. I. Introduction and morphology. Ann. Bot. Fennici 51: 240-252.

KATINAS, L. \& C. ZAVARO. 2014b. Endemism 
and taxonomy of Chaptalia (Asteraceae) in the Caribbean. II. Taxonomic treatment. Ann. Bot. Fennici 51: 253-266.

MCNEILL, J., F. R. BARRIE, W. R. BUCK, V. DEMOULIN, W. GREUTER, D. L. HAWKSWORTH, P. S. HERENDEN, S. KNAPP, K. MARHOLD, J. PRADO, W. F. PRUD'HOMME VAN REINE, G. F. SMITH, J. H. WIERSEMA \& N. J. TURLAND. (eds.) 2012. International code of nomenclature for algae, fungi and plants (Melbourne Code) adopted by the eighteenth International Botanical Congress Melbourne, Australia, July 2011. Regnum Vegetabile 154. Königstein: Koeltz Scientific Books.

PASINI, E., L. KATINAS \& M. R. RITTER. 2014. O gênero Chaptalia (Asteraceae, Mutisieae) no Rio Grande do Sul, Brasil. Rodriguésia 65: 141-158.
WATANABE, K., T. YAHARA, G. HASHIMOTO, Y. NAGATANI, A. SOEJIMA, T. KAWAHARA \& $\mathrm{M}$. NAKAZAWA. 2007. Chromosome numbers and karyotypes in Asteraceae. Ann. Missouri Bot. Gard. 94: 643-655.

WULFF, A. F., J. H. HUNZIKER \& A. ESCOBAR. 1996. Estudios cariológicos en Compositae. VII. Darwiniana 34: 213-231.

Recibido el 18 de mayo de 2014, aceptado el 1 de julio de 2014 . 